\title{
LOGISTICS CONTROLLING AS A TOOL OF PERFORMANCE IMPROVEMENT AT THE RUSSIAN ENTERPRISES
}

\author{
Victor Sergeyev \\ National Research University Higher School of Economics \\ Moscow, Russia, Myasnitskaya str. 20 \\ Ph.: +7 (495) 772-95-90, e-mail: viserg@bk.ru
}

\begin{abstract}
The article discovers the methodical approaches to the study of logistic activities controlling at the Russian enterprises. There are defined the phases of the controlling research management and described the initial sample of the enterprises surveyed. The methodology of the logistics controlling research is based on the system analysis, the methods of economic cybernetics, operations research, mathematical statistics, the theory of optimal decision-making, and the management theory.

The article presents the main results of the research specifying the state of logistics controlling at the Russian enterprises. The study has conducted a systematic analysis of the status and trends of logistics controlling at the domestic enterprises specialized in the industry, trade and services fields. Top managers of logistics departments in the Russian enterprises were interviewed about the logistics controlling. The survey was undertaken in the form of written and online surveys. The results are documented and processed by a special technique.
\end{abstract}

Keywords: Logistics controlling, survey, questionnaire, sample of enterprises, system analyses, research methodology

\section{Introduction and literature review}

At the present time the Russian companies require both the performance improvement due to the internal reserves and the company's image enhancement. In this situation business leaders are increasingly paying attention to logistics. To determine the bottlenecks in the logistics of the company for their subsequent removal and to achieve positive business results in logistics strategy logistic controlling is applied. Logistics controlling unifies accounting, planning, and management with information support of logistics business processes into a single system (Ballou, 2003, 2004; Hofer, Knemeyer, 2009).

According to the American experts in the field of logistics Stock, Lambert (2001), Smith (2007), Simchi-Levi, Chen, Bramel (1998) logistics controlling in business organizations is an isolated economic activity in the company which brings together accounting, planning, regulation, and information support of logistics business processes in a single system with the purpose to identify the reasons of the logistics efficiency reduction and to eliminate them and their consequences. Most of the foreign researchers agree on the allocation within the logistics both strategic and operational controlling (Coyle, Bardi, Langley, 2002; Luther, Jones, Sax, 2009; Śliwczyński, 2011). The purpose of the strategic controlling is to evaluate and adjust the logistics solutions (necessity of that depends on the environment), to assess the logistics strategy performance, to develop the alternative logistics strategies based on the market conditions, etc. The operational controlling is focused on the achievement and maintenance of the planned level of the logistics business processes efficiency, on the control of the current tasks solution within the logistics strategy, on the operational regulatory impact on the work progress. The procedure of the logistics controlling system development and deployment can be presented as a series of the following specific steps (Christopher, 2011; Stock, Lambert, 2001):

1. Definition and clear statement of the planned objectives of the logistics activities and purposes of the company.

2. Reflection of the goals of the logistics strategy in the system of the key performance indicators (KPI) of the logistics business processes.

3. Development of the system of differentiated management accounting and the methods of logistics KPI calculation and assessment.

4. Regular monitoring (measurement) of deviations of the actual values from the planned logistics KPI (normative, standard).

5. Adoption of management decisions in order to minimize the deviation of the actual values from the planned logistics indicators.

The ultimate goal of the logistics controlling at the company is to achieve the basic directions of the logistics strategy (Stock, Lambert, 2001; Ballou, 2004). Controlling of logistics activities leads to the 
application of the differential cost accounting methods which helps to calculate costs and results of logistic activities by different bases, for instance, such as product, customer, market, etc. In the process of controlling, information is collected and analyzed using the corporate information systems and the management accounting systems.

The logistics controlling system shall assess the efficiency and the effectiveness of business processes and decisions made; it shall define the contribution of each employee to the end result. So, the complexity of the logistics controlling system development is due to the intention to integrate financial and non-financial indicators. There is perhaps only one tool today - Balanced Scorecard (BSC) for the purpose mentioned that is confirmed by the numerous publications of the leading scientists in the field of logistics and SCM: Brewer, Speh (2000), Chopra, Meindl (2004), Niven (2005), Parmenter (2010), Smith D., Smith C. (2013).

The BSC is one of the most effective ways to assess the activities of the various divisions in the company, including logistics department. The important feature of the balanced scorecard is the coherence between the KPIs, the strategic objectives of the company and the actions to achieve them. The BSC complements the existing system of financial indicators which evaluate generally the already happened events by the prospective evaluations. The advantage of the balanced scorecard is the considerations of four directions of the company: finances, customers, internal activities (the internal business processes development), and training and education activities (Smith, 2007).

In the logistics case, first of all, the non-financial KPIs value the success of the logistics at the company in the long-run term. In addition, based on the BSC logistics controlling intend to assist in the decision-making process that means a detailed identification and analysis of the cause-and-effect relationships between the logistics results of the company. As the foreign experience shows, the application of SCOR-model in the supply chain for the purposes mentioned above is a good practice (Bolstorff, 2012; Chopra, Meindl, 2004; Śliwczyński, 2010; Yang, 2012).

Thus, the purpose of the logistics controlling is the maintenance of the sustainable contribution to the successful operations of the company and the support of the logistics projects implementation. Logistics controlling facilitates the persistent receipt of the targeted value of the logistics metrics in terms of logistics services quality, costs, lead time and inventory levels. The positive effect of the logistics controlling implementation is the coordinated actions of all participants in the supply chain to the achievement of the efficiency and effectiveness of logistics business processes.

The topicality of the article is determined by the necessity to be familiar with the state of the logistics controlling in the modern Russian market and to confirm the presence of important relationships between the components of the logistics activities such as logistics strategy and emergence of logistics problems due to inter-organizational and cross-functional coordination. Moreover, the Russian companies have a desire to stay abreast of key trends and elaborations in the field of logistics, in particular, logistics controlling of enterprise, with the aim of achieving the highest position in the Russian market.

\section{Methodology of the research}

Conducted by the author in the International Center of Training in Logistics at the National Research University Higher School of Economics (HSE) in 2012-2013, the investigation of the logistics controlling at the Russian enterprises is based on the analysis of the data received from the on-line survey of Top Managers in Logistics at the Russian companies. The survey is intended to create the directions of the logistics controlling improvement at the Russian enterprises and provide the ideas how to develop the effective system of the logistics KPI evaluation.

The objects of the study are 145 known Russian enterprises the management of which has agreed to take part in the study of the logistics controlling.

The subject of the study is the organizational and methodological aspects of the logistics controlling organization at the Russian enterprises as well as the analysis of how the logistics KPIs impact the business efficiency.

The survey was carried out in the form of the written and on-line questionnaire of the Top Managers in Logistics (Directors, Heads of Logistics Departments and Divisions, Coordinators of Logistic Processes, Integrated Logistics Managers, etc.). The analysis has identified the gaps in the following components of the logistics controlling at the German and Russian enterprises:

1) in the organizational structure of management by the logistics department,

2) in the logistics costs account,

3 ) in the logistics budgeting,

4) in the reporting,

5) in the logistics controlling special tools, 
6) in performance evaluation taking into account principles of logistics,

7) in the controlling of the supply chain efficiency.

The use of the international best practice such as controlling, analysis and audit of the logistics activities and the supply chain management (SCM) tested by the leading worldwide enterprises can become a reliable source how to make strategic plans, undertake benchmarking, GAP-analysis and improve efficiency of the supply chains at the Russian business. In addition it can be the foundation for the discussions on a global logistics community.

At the international level such research is becoming very crucial as it benchmarks logistics indicators at the Russian companies and at the top companies around the world, especially German ones recognized as leaders according to the logistics performance index in the rating of the World Bank. The study provides a basis for the development of the new requirements for global supply chains logistics performance taking into account customers needs, innovative solutions in logistics and complicated quality of the regulative and control methods. This all confirms that recognizing the complexity associated with the expansion of the logistics boundaries the leading companies develop global logistics and supply chain strategies designed to monitor, to respond to, and to manage this complexity.

The methodology of the logistics controlling research is based on the system analysis, the methods of economic cybernetics, operations research, mathematical statistics, the theory of optimal decisionmaking, and the management theory.

The methodology and the methodological guidelines of the study management suggest three interrelated phases.

Phase 1: Literature review and issue analysis.

A detailed literature review of the previous research on the specified area has been carried out. The Internet sources, in particular, consulting reports on the logistics and SCM controlling were examined. Next step distinguishes the key issues in them. During the analysis our own statistical methods of assessing the significance of the problems in logistics controlling were used.

Content analysis technique allows reviewing a huge number of the scientific articles in the Internet in order to narrow the range of problems in the controlling of the logistics activities at the Russian enterprises. Further, a list of keywords for later analysis was formed. A number of large databases among which Bloomberg supply chain analysis terminal, Lexis-Nexus, Ibis, Business Source Premier and several other databases were revised. As the last step of the phase the list of the investigating problems in logistics and SCM controlling was summarized and filtered.

Phase 2: Survey of managers and performers.

Based on the content analysis a preliminary list of key issues that reflect the problems of scientific research in the field of logistics controlling was created. Using these data, there was developed the questionnaire for the interview and the protocol for conducting negotiations with the key business respondents. Later on a list of potential respondent companies on the topics of the research (the sample of the research) was prepared; the questionnaire was sent by e-mails; online surveys and interviews were conducted.

Phase 3: Survey analysis and reporting.

From the methodology point of view, the study is based on the proof or disproof hypotheses raised. In other words, firstly, possible relationships between the questions of the research which cover the rational behaviour of the company in the field of logistics and SCM are specified, and then the responses received check the validity of presuppositions.

Having analyzed the statistical data obtained from the completed questionnaires and having disclosed the deviations in the company's activities in the field of logistics and SCM controlling from the rational way, the factors that can potentially affect the logistics activities of the company are identified, it means that the factor analysis is conducted. In conclusion of the phase, the scientific report is drawn up.

One of the main purposes of the study is to test the hypotheses that there are interconnections between the business performance and the logistics metrics. During the study of each hypothesis a number of statistical data summarized in the table is considered. For ease of the analysis, and in order to be able to compare replies, the number of responses is shown in the tables with the following details: there is specified the number of respondents covered by the each question as a percentage of the total number of respondents and the number of representatives of each industry related to the specific question as a percentage of the total number of respondents of each industry respectively.

Also, there is calculated the percentage of respondents of each industry in the total number of respondents (Table 1), the number of companies that have logistics problems due to both the lack of cross-functional coordination at the enterprises and the lack of coordination with partners on every point 
of the first part of the hypothesis "a strategy, goals, processes". Thus, there is defined the number of the total sample, the number of the respondents to a particular question and the share of each industry.

Table 1. The number of respondents in each industry and the percentage of each industry in the total sample

\begin{tabular}{|c|c|c|}
\hline Car industry & 4 & $2,8 \%$ \\
\hline Woodwork and timber industry & 3 & $2,1 \%$ \\
\hline Wholesale and retail trade industry & 49 & $33,8 \%$ \\
\hline Publishing and bookselling & 3 & $2,1 \%$ \\
\hline Textile, clothing and footwear industry & 5 & $3,4 \%$ \\
\hline Industry of logistics services & 21 & $14,5 \%$ \\
\hline Petroleum and mining industry & 17 & $11,7 \%$ \\
\hline Food industry & 12 & $8,3 \%$ \\
\hline Construction and repair industry & 4 & $2,8 \%$ \\
\hline Pharmaceutical industry & 5 & $3,4 \%$ \\
\hline Chemical industry & 7 & $4,8 \%$ \\
\hline Electronics and electrical engineering and technologies & 15 & $10,3 \%$ \\
\hline
\end{tabular}

In processing the data of the survey it was necessary to take into account certain risks of reliability and accuracy of the respondents' propositions about the effectiveness of logistics controlling as a whole, in each industry and in each type of business. Therefore, there are limitations on the dissemination of the survey findings on the logistics controlling in the market or in each industry (if the conclusions are based on the data obtained from the respondents of each industry). These risks include possible insincerity of respondents caused by the internal corporate reasons, various sample sizes in different industry, a relatively large number of respondents who did not respond to a particular survey question due to the necessity of keeping business secrets.

\title{
3. The results of the study data
}

We begin with a general description of the logistics situation in light of the division companies by industry. For this we consider six questions: 1 - logistics as core competence; 2 - the importance of quality to meet customers; 3 - the availability of logistics sourcing; 4 - the availability of logistics goals, 5 - devotion time to logistics and SCM, 6 - measured logistics performance indicators and availability of information for their measurement.

1."Logistics is a key competence in your company?" Figure 1 shows the responses of managers and specialists of participating companies. The figures for each sector reflect the percentage of participants who answered yes to this question. As expected, the greatest seriousness to impose logistics companies operating in the field of logistics services. In the range of $40-50 \%$ of the companies answered "yes" the company is located in the automotive industry, light industry, as well as the scope of the distribution and retailing.

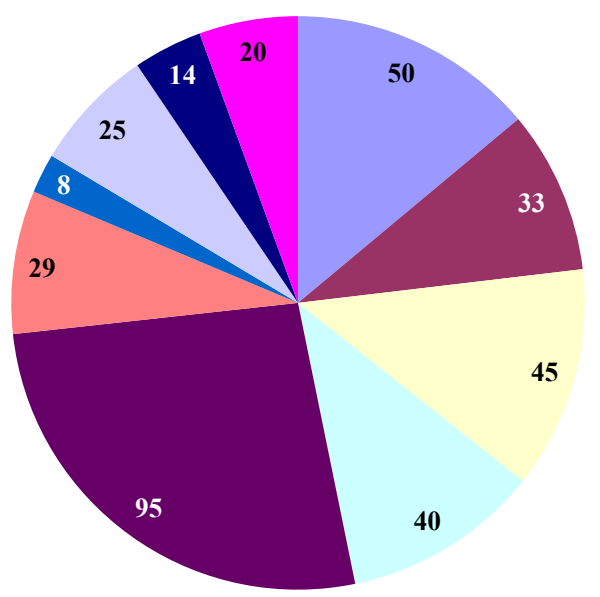

\author{
Automotive \\ - Wood and paper \\ Distribution and retail \\ Light industry \\ n Logistics services \\ -Oil, gas and mining \\ - Food \\ Construction and maintenance \\ - Chemical \\ Electrical engineering
}

Figure 1. Percentages of companies for which Logistics is a key competence 
In the first two cases, the output of logistics in the category of key competence, likely due to high volume turnover of raw materials, work in process, finished goods within companies, as well as due to the inability of external logistics providers to provide the required level of logistics service, so they have to be oriented towards logistics operations on their own. As for companies in distribution, $45 \%$ of positive responses - it is a very low figure, since the main objective in this sector is the distribution of products in the supply chain, and this is an integral part of the logistics.

2. "What is the quality of the logistics to meet your clients?" Figure 2 shows the responses to this question. It is important to note that virtually in every industry; most companies objectively note the high impact of logistics on customer satisfaction. For a small percentage of companies in the areas of distribution, retail, logistics and light industry, moreover, plays a crucial role.

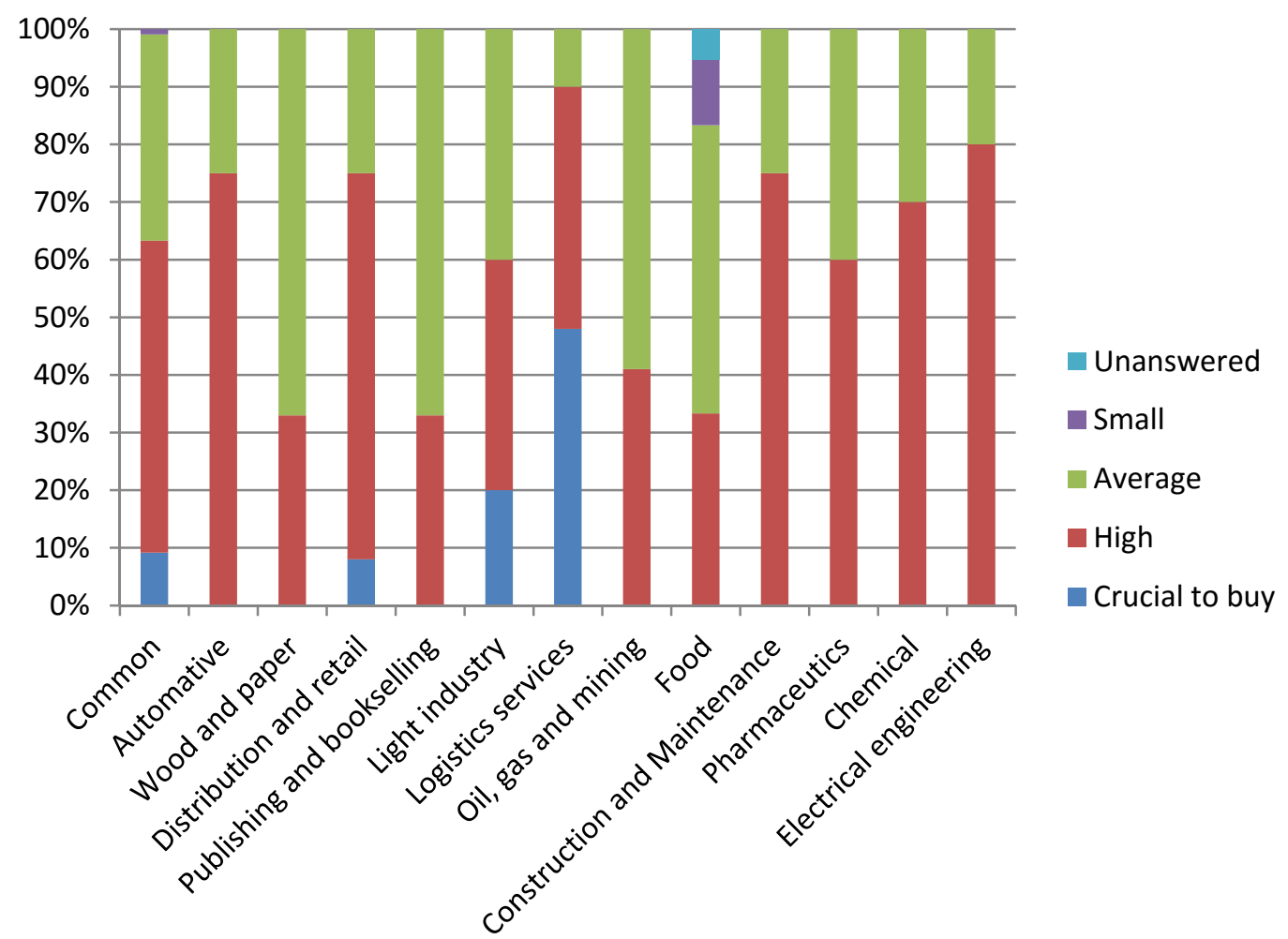

Figure 2. Role of logistics in satisfaction of customers' requirements

For companies engaged in distribution and retail, the importance of logistics is the need for timely delivery, supply flexibility (ability to respond to changing conditions on the part of customers and external changes) to maintain the required quality of delivery. In light industry, some companies faced with changes in customer preferences (trend in fashion), thus requiring manufacturers to create something new, and timely provision of outlets this product to meet customer expectations. As in the previous question, leadership remains for companies providing logistics services. On the other hand, a surprise is the fact that more than half of such companies' logistics is not a decisive factor in customer satisfaction.

3. "Do you have a written logistics strategy communicated to all members of company? Figure 3 shows the responses to this question. On average, $40 \%$ of companies in the field of electrical engineering, pharmaceuticals, and oil, gas and mining industries have clearly expressed logistics strategy. Although most of these companies $40 \%$ in each sector do not produce logistics as core competence, as their activity is still primarily focused on the production and extraction, they understand the importance of logistics and, most likely, logistics operations are implemented independently, without focusing on logistics providers. One of the main reasons for insourcing of logistics for these industries can serve significant 
numbers of companies that require extensive and strict control of material flows and associated with the logistic point of view. Today, however, this requirement cannot be met in outsourcing of logistics, due to the insufficient level of quality of logistics service providers. In the oil and gas and mining industry large amounts of raw materials transported through pipelines, which requires a certain infrastructure and transportation under similar conditions using rail transport is unprofitable.

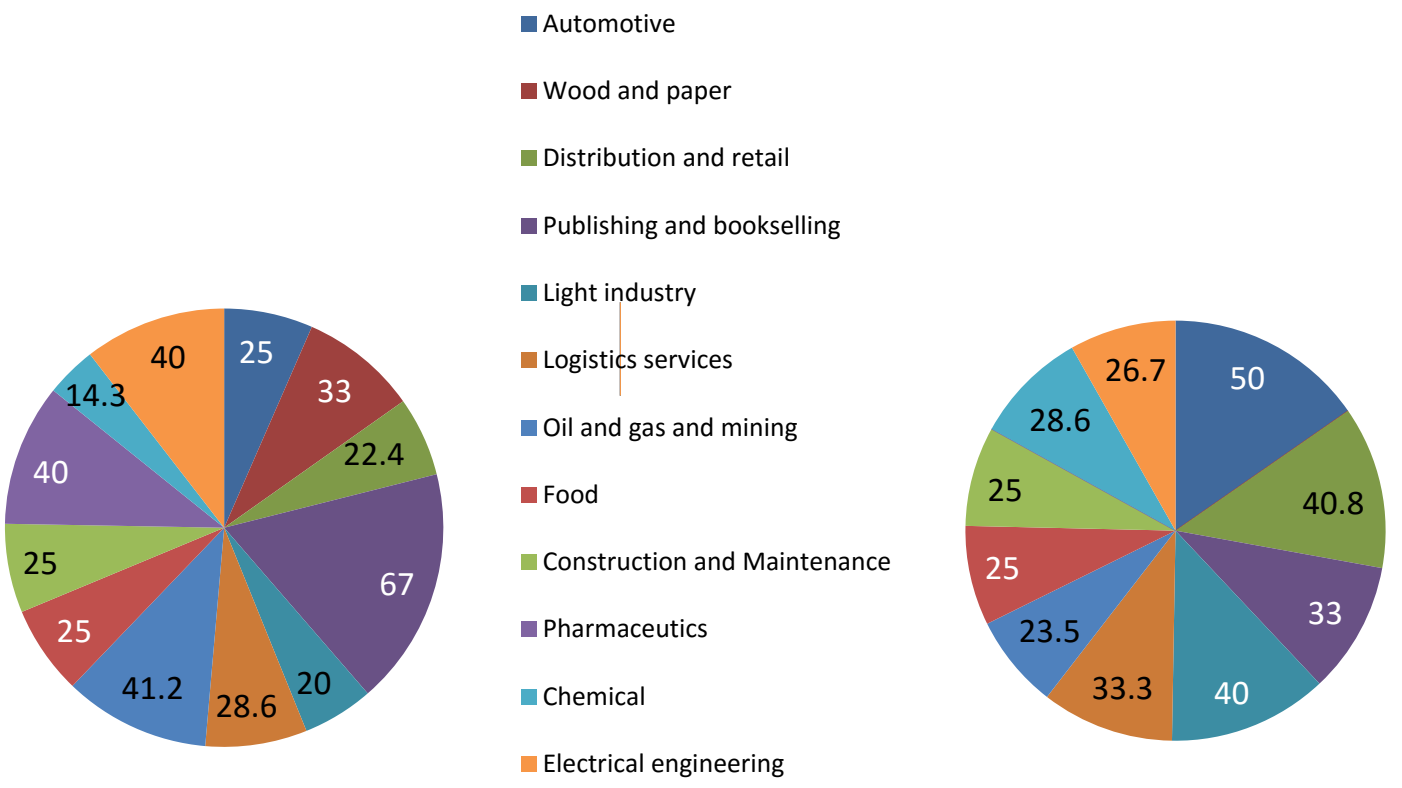

Figure 3. The presence of logistics strategy in the company

In the pharmaceutical companies often faced with the need to work with a wide range of medicines, tablets, etc. and with plenty of places in retail sales, and this involves a complex organization, marketing logistics and control execution of logistics operations. In electrical engineering a possible factor in the refusal of logistics outsourcing is part of new items, updating the product range, customer preferences change, requiring a rapid response on the part of all these changes in order to maintain the company's performance and to obtain a high return on core activities. In the oil and gas and mining industries and fields of electrical engineering, in addition to $40 \%$ of companies with a strong logistics strategy has added, on average, $25 \%$ of companies in each industry, noted the presence in the enterprise strategy, though not explicitly.

Much worse is the case in the areas of logistics services and distribution and retail. Among the companies providing logistics services, only $30 \%$ have a specific sourcing explicitly and $30 \%$ - in an implicit form. In distribution and retail these figures $22 \%$ and $40 \%$ respectively. In companies whose activities are focused on logistics, lack of sourcing leads employees and managers themselves sometimes to misunderstanding of what is necessary to strive in the short and long term. Moreover, within the organization there cannot be a unified logistics system with interconnected units, clearly understands landmark Development Company as a whole and aware of what it is worth emphasizing.

4. “Are there output from sourcing mandatory and measurable goals logistics?" On this issue, treatment response is shown in Figure 4. If we compare the responses by the presence of strategies and responses by the presence of goals, there is an approximate equality in the results. There is the availability of logistics goals of more companies in the sectors of electrical engineering, construction and repair, food industry and logistics services. In the latter case, however, only a third of all companies have explicit goals and logistics another third goal has implicitly. 


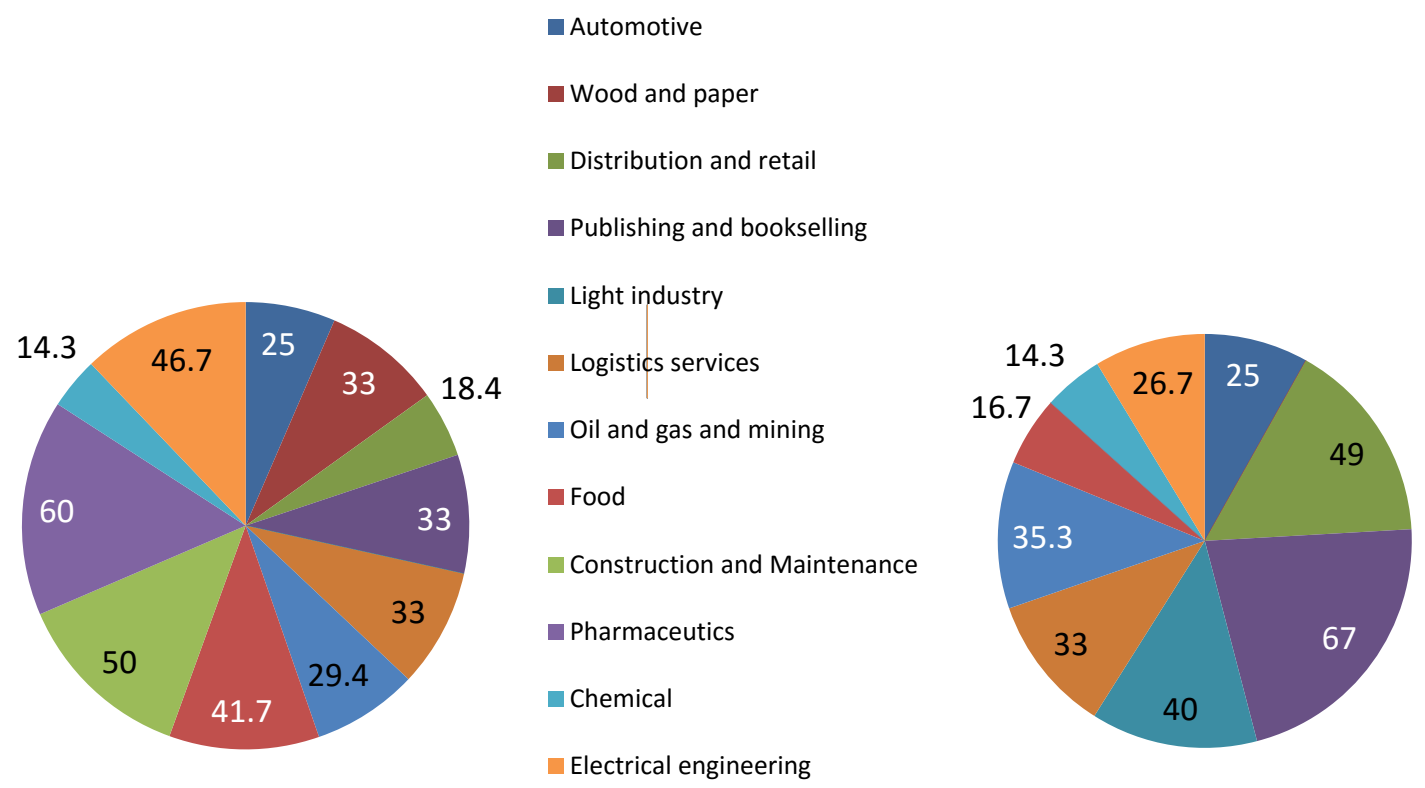

Figure 4. The presence of logistics strategy in the company

Thus, a third of companies offering their services in the logistics market do not have logistics purposes, allow a clear understanding of the task to implement them in the company. In the area of distribution and retail situation worse, since the goal explicitly has an even smaller number of companies: $18 \%$ vs. $22 \%$ in the issue regarding strategy.

5. "How often senior management devotes time to logistics and SCM?" The results obtained are displayed in Figure 5. Despite the very large proportion of the companies did not respond, most responding companies dedicates time on logistics at least several times a month. The least attention paid to logistics in the construction, repair, and chemical industries.

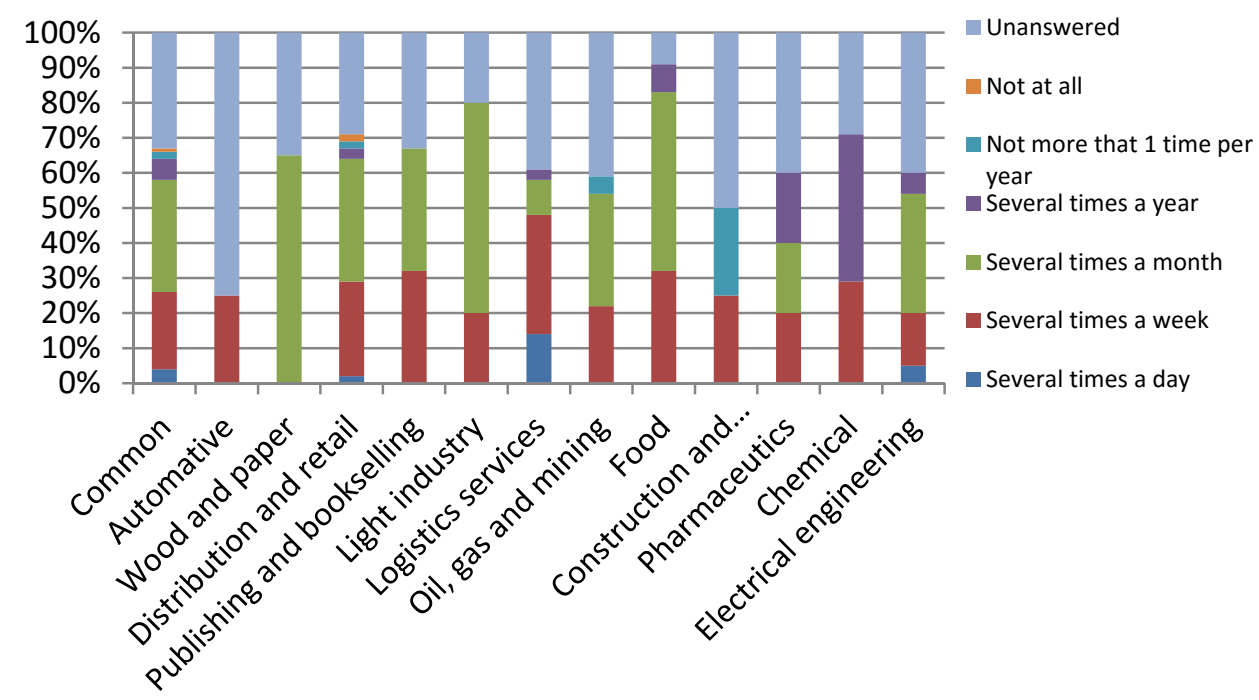

Figure 5. Frequency of logistics and supply chain management issues considerations by senior management of companies in different industries 
Perhaps the lowest frequency is related to a very stable situation on the real estate market and the market of household chemicals. In the areas of publishing and bookselling, light industry, food industry and electrical time logistics management pays up to several times a week (in the field of electrical engineering, up to several times per day).

One of the main causes of this is the instability of work on the part of partner companies, changes in demand, and the availability of regular innovations on the part of producers. All this requires a relatively rapid adaptation changing market situation, so tasks in companies are placed on small deadlines and regularly agreed.

6. "Which logistics performance indicators are used in your company? Do you have all necessary data for metrics' calculation?"

Figure 6 shows the responses on this issue.

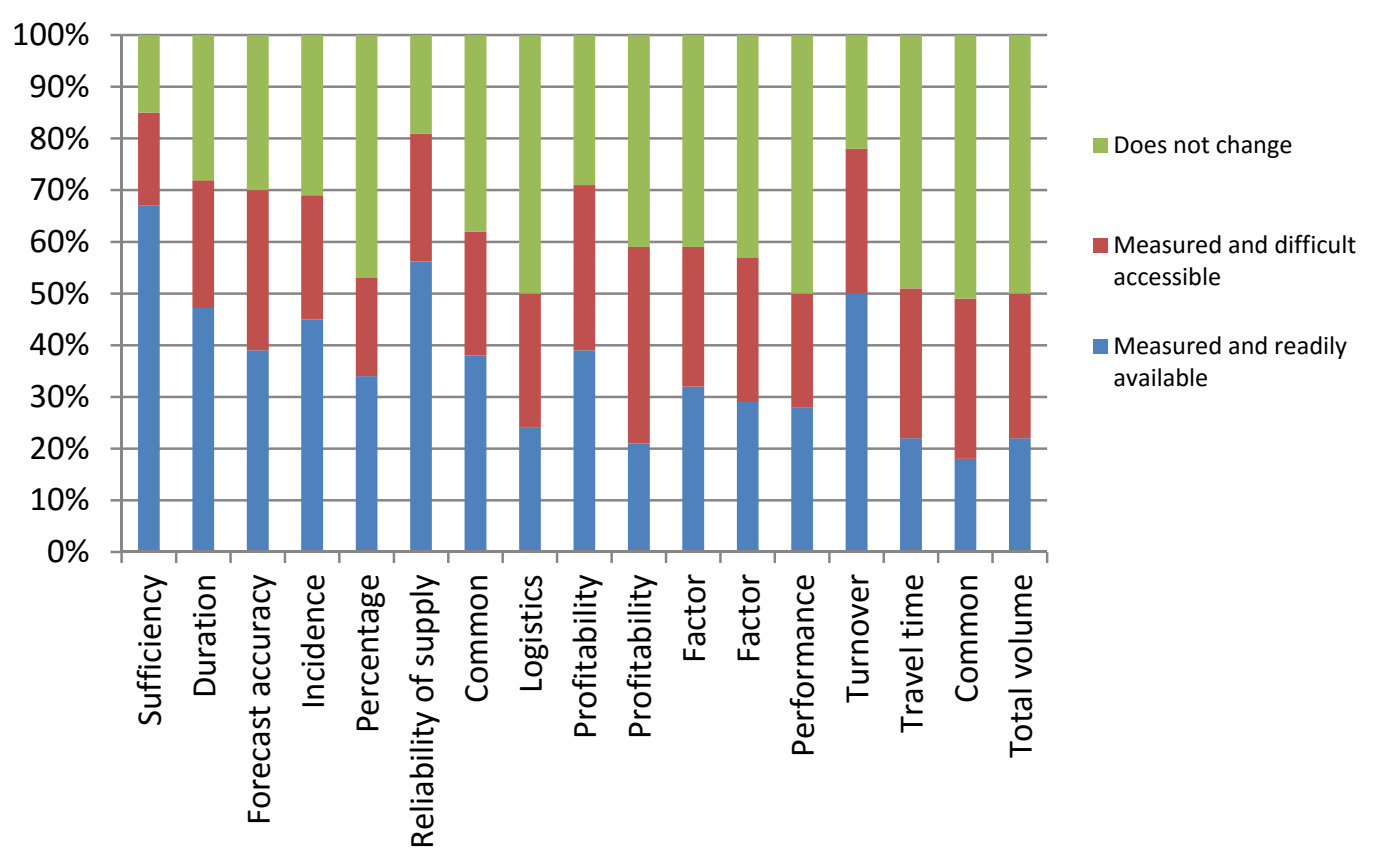

Figure 6. Measured logistics performance indicators and availability of information

The indicators for the six areas of research included the following:

$\checkmark$ Internal focus: the adequacy of reserves, the duration of the logistics cycle, forecasting accuracy, the frequency of stock-outs.

$\checkmark$ Customer focus: the percentage of perfect orders, delivery reliability.

$\checkmark$ Logistics costs: total logistics costs (as a percentage of turnover), logistics costs per one order.

$\checkmark \quad$ Profit and Shareholder Value: return on assets, return on invested capital.

$\checkmark$ Productivity logistics assets: utilization of storage assets and means of transport, logistics staff productivity, inventory turnover.

$\checkmark \quad$ The focus of the supply chain: the passage of the order in the supply chain, general logistics supply chain costs, the total inventory in the supply chain.

In most of the analyzed companies are settled in terms of adequacy of reserves $(83 \%)$, inventory turnover $(78 \%)$, return on assets $(81 \%)$, reliability of supply $(84 \%)$. Least often indicators are calculated act percentage flawlessly executed orders $(51 \%)$, logistics costs per order $(50 \%)$, employee productivity, logistics (50\%), while passing the order in the supply chain $(51 \%)$, total logistics costs of the supply chain $(48 \%)$, the total inventory in the supply chain (49\%). Moreover, it should be noted that for each indicator 
on average for slightly more than half of the respondents in terms of the calculations are easy enough in terms of getting the original data.

In the following part of the article the example of hypothesis testing in the context of logistic controlling is considered.

The hypothesis concerns the analysis of the links between the compatibility of logistics information systems and the information availability to the partners in supply chain. The link can be provided by six types of information: demand and availability of stocks at points of sale; inventory levels and forecast of customer demand; inventory levels of the central storage; production plans; sales promotion programs; readiness of suppliers to supply goods in time. Results for the first three types of information are shown in the Tables $2-4$, respectively.

Table 2. Results for information on demand and availability of stocks at points of sale

\begin{tabular}{|l|l|l|l|}
\hline $\begin{array}{l}\text { Demand and availability of stocks at points } \\
\text { of sale }\end{array}$ & Information availability to partners & & \\
\hline $\begin{array}{l}\text { Compatibility of logistics information } \\
\text { systems }\end{array}$ & Low & Middle & High \\
\hline Fully integrated & 3 & 1 & Total \\
\hline Integrated some modules & 3 & 7 & 2 \\
\hline $\begin{array}{l}\text { Theoretically compatible, however the } \\
\text { integration is absent }\end{array}$ & 3 & 14 & 11 \\
\hline Incompatible & 1 & 5 & $\mathbf{3}$ \\
\hline $\begin{array}{l}\text { Absence of information about the information } \\
\text { of partners in supply chain }\end{array}$ & 9 & 19 & $\mathbf{2 1}$ \\
\hline Total & $\mathbf{1 6}$ & 9 & $\mathbf{6}$ \\
\hline
\end{tabular}

As it is seen from the results of the Table 2 the largest proportion of the respondents notes an average level of the information availability in the supply chain under the absence of any information about the IT-systems of their partners. Moreover, it turns out that on average about $40 \%$ of the respondents do not have information about the partners, but still in some cases partners have been well-provided with data. This very strange links can be explained by the fact that these companies are not interested in the integration of information with their partners, believe in sufficiency of the current data exchange. The leaders do not have any stimulus to establish a more accurate, fast and detailed information relationships and use the potentials of integrated IT-systems, about which perhaps they do not have sufficient knowledge.

Table 3. Results for information on inventory levels and forecast of customer demand

\begin{tabular}{|l|l|l|l|l|}
\hline $\begin{array}{l}\text { Inventory levels and forecast of customer } \\
\text { demand }\end{array}$ & $\begin{array}{l}\text { Information availability to } \\
\text { partners }\end{array}$ & Middle & High & Total \\
\hline $\begin{array}{l}\text { Compatibility of logistics information } \\
\text { systems }\end{array}$ & Low & & 2 & \\
\hline Fully integrated & 4 & 8 & 9 \\
\hline Integrated some modules & 2 & 14 & 9 & $\mathbf{2 1}$ \\
\hline $\begin{array}{l}\text { Theoretically compatible, however the } \\
\text { integration is absent }\end{array}$ & 3 & 2 & $\mathbf{2 5}$ \\
\hline Incompatible & 10 & 14 & $\mathbf{5}$ \\
\hline $\begin{array}{l}\text { Absence of information about the } \\
\text { information of partners in supply chain }\end{array}$ & $\mathbf{1 9}$ & $\mathbf{4 0}$ & $\mathbf{2 9}$ \\
\hline Total & & $\mathbf{2 3}$ \\
\hline
\end{tabular}

Table 4. Results for information on inventory levels of the central storage

\begin{tabular}{|l|l|l|l|l|}
\hline Inventory levels of the central storage & $\begin{array}{l}\text { Information availability to } \\
\text { partners }\end{array}$ & & Middle & High \\
\hline $\begin{array}{l}\text { Compatibility of logistics information } \\
\text { systems }\end{array}$ & Low & & 1 & 3 \\
\hline Fully integrated & 2 & 13 & $\mathbf{3}$ \\
\hline Integrated some modules & 2 & 13 & 7 \\
\hline $\begin{array}{l}\text { Theoretically compatible, however the } \\
\text { integration is absent }\end{array}$ & 3 & 3 & $\mathbf{2 2}$ \\
\hline Incompatible & 13 & 16 & $\mathbf{2 5}$ \\
\hline $\begin{array}{l}\text { Absence of information about the } \\
\text { information of partners in supply chain }\end{array}$ & $\mathbf{2 0}$ & $\mathbf{4 6}$ & $\mathbf{6}$ \\
\hline Total & & $\mathbf{2 6}$ \\
\hline
\end{tabular}


A quarter of companies has been familiar with the information system employed by a partner. These companies are going to integrate with partners in the nearest future. The other quarter of the respondents has already had certain modules integrated with supply chain partners. These two arguments prove the interest of more than a half of the companies participated in the study in cooperation with partners and, as a consequence, increase of the logistics and supply chain effectiveness via better exchange of information, statistical and other data.

It is an isolated case when the information systems are not compatible to the partners' ones or all modules of the systems are completely integrated. However considering these three findings together there is a positive correlation between the two points: the enhancing integration of the different modules of information systems increases the level of information availability to the partner companies. Thus the posed hypothesis is supported by the three findings which mean that companies integrate their systems properly and efficiently use them for monitoring inventory, forecasting customer demand and fluctuations in it.

\section{Conclusion}

The overall conclusions of the logistics controlling study are the following:

1. The majority of companies (95\%) evaluate the effectiveness of logistics on the base of operational logistics costs.

2. Only about $13 \%$ of the surveyed companies have a logistic strategy and establish it consciously.

3. Only $20 \%$ of companies separate a function of inventory management in their organisational structure, and only $14 \%$ of these companies give the function to the logistics department.

4. In the samples studied, $60 \%$ of companies face with conflict situations affecting the logistics department activities.

5. About $10 \%$ of the industrial companies in the surveyed samples give the functions of production logistics into the logistics department, these functions are performed by the production department in the other companies.

6. About a third of the companies specify the function of service policy development, and only $11 \%$ of them give the function into the logistics department.

7. The controlling office in the logistics department has been separated in only $14 \%$ of the surveyed companies.

8. In the investigated samples coordinating logistics functions have been never outsourced.

9. The findings of the state of logistics controlling at the Russian enterprises show that ABC / $\mathrm{XYZ}$ - analysis $(27 \%)$, the model of strategic profit $(23 \%)$, the model of the economic order quantity $(21 \%)$, process costs accounting (20\%) and benchmarking $(17 \%)$ are the most relevant and regularly implemented tools in the responding companies.

\section{References}

1. Ballou, R.H. (2003) Business Logistics. Supply Chain Management. Prentice Hall. 676 p.

2. Ballou, R.H. (2004) Business logistics, supply chain management - Planning, organizing, and controlling the supply chain, 5 ed., Pearson Education.

3. Bolstorff, P. (2012) Supply chain excellence: a handbook for dramatic improvement using the SCOR model, 3-rd edition. New York: AMACOM. 304 p.

4. Brewer, P.C., Speh, T.W. (2000) Using the Balanced Scorecard to Measure Supply Chains Perfomance. Journal of Business Logistics 21 (1), pp. 75-93.

5. Chopra, S., Meindl, P. (2004) Supply Chain Management. Strategy Planning and Operations. 2nd edition. Pearson Educational International Ltd, 2004. 661 p.

6. Coyle, J.J., Bardi, J.E., Langley, J.J. (2002) Management of Business Logistics: A Supply Chain Perspective. 7th edition. South-Western College Pub. 672 p.

7. Hofer, Adriana Rossiter, Knemeyer, A. Michael (2009) Controlling for logistics complexity: scale development and validation. The International Journal of Logistics Management. №2 (20), pp. 187200.

8. Logistics and Supply Chain Management (4th Edition) (Financial Times Series) by Martin Christopher (Jan 6, 2011) Logistics and Supply Chain Management (4th Edition) (Financial Times Series) by Martin Christopher (Jan 6, 2011).

9. Niven, Paul R. (2005) Balanced Scorecard Diagnostics: Maintaining Maximum Performance. Published by John Wiley\&Sons, Inc., Hoboken,New Jersey. 189 p. 
10. Parmenter, D. (2010) Key Performance Indicators: Developing, Implementing and Using Winning KPI's. New Jersey, USA: John Wiley \& Sons, inc. 299 p.

11. Robert Luther, Colwyn Jones, Astrid Sax. (2009) Experiencing change in German controlling: management accounting in a globalising world (Research executives summaries series). Chartered Institute of Management Accounting. №5 (12). 6 p.

12. Śliwczyński Bogusław (2010) The reference model of supply chain operational controlling in value management. Electronic Scientific Journal of Logistics. №3, pp. 21-35.

13. Śliwczyński Bogusław. (2011) Operational Controlling - a Tool of Translating Strategy into Action. Electronic Scientific Journal of Logistics. №5, pp. 45-58.

14. Smith D., Smith C. (2013) What's Wrong with Supply Chain Metrics? Strategic Finance. October, pp. 27-33.

15. Smith, R. F. (2007) Business process management and the balanced scorecard: using processes as strategic drivers / R. F. Smith. - Hoboken: John Wiley \& Sons. 227 p.

16. Simchi-Levi D., Chen X., Bramel J. (1998) The Logic of Logistics: theory, algorithms, and applications for logistics and supply chain management. Springer Science+Business Media Inc. $562 \mathrm{p}$.

17. Stock J., Lambert M. (2001) Strategic Logistics Management. (4th Edition). - McGraw-Hill, Irwin. $798 \mathrm{p}$.

18. Yang Jie. (2012) A structural model of supply chain performance in an emerging economy. International Journal of Production Research. №14 (50), pp. 3895-3903. 